\title{
Implementação dos mecanismos de governança de tecnologia da informação em uma universidade pública
}

\author{
Richardson Silveira Almeida Mestre em Políticas Públicas e Segurança Social. Universidade Federal do Recôncavo da Bahia \\ (UFRB) - Brasil. richardson.silveira.almeida@gmail.com \\ Warli Anjos de Souza Doutor em Economia Aplicada. Universidade Federal do Recôncavo da Bahia (UFRB) - Brasil. \\ warlianjossouza@gmail.com
}

\section{RESUMO}

0 presente artigo tem como foco investigar a implementação dos mecanismos de governança de tecnologia da informação (TI) na Universidade Federal do Recôncavo da Bahia (UFRB), Brasil. Neste contexto, o principal objetivo é indicar quais os mecanismos necessitam de ações de melhorias. Para tanto, utilizou-se de questionário, com uso da escala Likert de cinco pontos, para indicar o grau de atitude dos tomadores de decisão da universidade acerca da implementação dos mecanismos de governança de TI. Adicionalmente, buscou-se evidências de implementação no Plano de Desenvolvimento Institucional (PDI) 2015-2019, nos relatórios de gestão de 2015 e 2016, no relatório de auto avaliação institucional 2015-2017, e no site da instituição. A análise realizada indicou que a implementação dos mecanismos investigados na UFRB encontrava-se em um estágio embrionário, com inércia das estruturas de tomada de decisão estratégica de TI, e ausência da definição de princípios, políticas e modelos de Tl, o que compromete a implementação das demais categorias dos mecanismos de governança de TI. A constatação acerca do estágio embrionário da implementação dos mecanismos de governança de TI permitiu concluir ausência de alinhamento estratégico entre TI e negócio e, por consequência, comprometimento da entrega de valor proporcionado pela TI para a comunidade acadêmica.

Palavras-chave: Habilitadores do COBIT 5. Mecanismos de Governança de Tecnologia da Informação. Percepção de Gestores de Negócio.

\section{Implementation of mechanisms of information technology governance in a public university}

\begin{abstract}
This article focuses on the implementation of information technology (IT) governance mechanisms at the Federal University of Recôncavo da Bahia (UFRB), Brazil. In this context, the main objective is to indicate which mechanisms need improvement actions. To do so, a questionnaire was used using the five-point Likert scale to indicate the degree of attitude of university decision-makers about the implementation of IT governance mechanisms. In addition, we sought evidence of implementation in the Institutional Development Plan (MDP) 2015-2019, in the management reports for 2015 and 2016, in the institutional self-assessment report 20152017 , and on the institution's website. The analysis indicated that the implementation of the mechanisms investigated at UFRB is at an embryonic stage, with the inertia of the strategic IT decision-making structures, and the absence of the definition of IT principles, policies and models, which hinders the implementation of the other categories of IT governance mechanisms. The findings regarding the embryonic stage of the implementation of IT governance mechanisms has led to the conclusion that there is no strategic alignment between IT and business and, consequently, a hindrance to the delivery of value provided by IT to the academic community.
\end{abstract}

Keywords: COBIT Enablers 5. Governance Mechanisms for Information Technology. Perception of Business Managers. 


\section{INTRODUÇÃO}

A governança de tecnologia da informação (TI) apresenta-se como tema relevante nos ambientes corporativos. De acordo com Weill e Ross (2006), o custo, a abrangência e o entendimento do valor da TI são alguns dos motivos que justificam o debate deste tema. Por entender que uma boa governança de TI traz resultados positivos para as organizações, diversos autores e entidades têm se dedicado a desenvolver modelos de governança de TI que podem ser adaptados à realidade dos diversos ambientes corporativos. Um dos modelos mais usados para realizar avaliações e implementações da governança de TI tanto em organizações públicas quanto nas organizações privadas é o Control Objectives for Information and Related Technologies (COBIT), por reunir um conjunto de boas práticas de governança de $\mathrm{TI}$ reconhecidos internacionalmente.

A importância da implementação dos mecanismos de governança de TI tem exigido do Tribunal de Contas da União (TCU) realizar levantamento da situaçã̃o da governança de TI a cada 2 (dois) anos em órgãos e entidades da Administração Pública Federal (APF). 0 último levantamento disponibilizado pelo TCU, em 2016, revelou que a situação da governança de TI está longe de ser aceitável. De acordo com o TCU, desde o primeiro levantamento (Acórdão 1.603/2008 - Plenário), aconteceram evoluções discretas nos níveis de adoção das práticas avaliadas pelo Tribunal. Entre as organizações que apresentaram menor capacidade de governar sua TI, estão as Instituições Federais de Ensino Superior (IFES), e entidades vinculadas ao Ministério da Ciência, Tecnologia, Inovações e Comunicações e ao Ministério da Cultura. Para o TCU, estas organizações não tratam a TI como parte integrante dos seus negócios, o que compromete 0 atendimento das demandas da sociedade (TCU, 2017).

Entre as organizações que apresentaram menor capacidade de governar a sua TI no levantamento realizado pelo TCU no ano de 2016, estão as IFES (TCU, 2017). Organizações que fazem parte da APF e que promovem o desenvolvimento científico e tecnológico no país. Para o alcance de seus objetivos, estas instituições dependem da utilização eficiente da TI para entregar bons resultados a seus usuários. Neste sentido, não somente o TCU, como também a comunidade acadêmica desempenha um papel importante ao realizar pesquisas com o objetivo de promover ações de indução da governança de TI na APF.

Cavalcanti Filho (2011) pesquisou sobre a influência da governança de TI nas IFES. De acordo com o autor, apesar da dependência crítica da TI, por estas instituições, comprovou-se que o tema governança de TI ainda é pouco difundido entre os tomadores de decisão, o que compromete as estratégias de negócio. De maneira geral, a pesquisa revelou que a situação da governança de TI nas IFES encontrava-se em um estágio incipiente, revelando os riscos da gestão dos gastos públicos com TI. De forma mais específica, através de um estudo de caso, Nascimento (2014) pesquisou sobre o alinhamento estratégico da TI na Universidade Federal do Rio Grande do Norte (UFRN). 0 estudo revelou que o setor responsável pela TI na UFRN executava as demandas à medida que surgiam as necessidades de negócio, não participando diretamente de decisões estratégicas. Segundo o autor, a governança de TI naquela universidade encontrava-se em um estado incipiente, com ausência de definições específicas para a TI dentro do Plano de Desenvolvimento Institucional (PDI) e a ausência de um Plano Diretor de TI (PDTI).

Considerando os levantamentos do TCU acerca da governança de TI no sentido de promover ações de indução, e a importância de pesquisas realizadas no meio acadêmico, como a de Cavalcanti Filho (2011) e Nascimento (2014), este artigo se propõe a responder a seguinte questão: como os mecanismos de governança de TI estão sendo implementados na Universidade Federal do Recôncavo da Bahia (UFRB) conforme a percepção dos tomadores de decisão e as evidências documentais?

Para responder à questão de pesquisa apresentada, buscou-se atingir o seguinte objetivo geral: estudar a implementação dos mecanismos de governança de TI na UFRB conforme a percepção dos tomadores de decisão e as evidências documentais para indicar quais os mecanismos necessitam de ações de melhorias.

Para atingir o objetivo geral definiu-se os seguintes objetivos específicos:

a) Identificar a percep ção dos principais tomadores de decisão da UFRB acerca da implementação dos mecanismos de governança de TI; 
b) Examinar documentos da instituição a fim de evidenciar aspectos da implementação dos mecanismos de governança de Tl;

c) Confrontar a percepção dos principais tomadores de decisão da UFRB em relação implementação dos mecanismos de governança de TI com as evidências documentais a fim de indicar quais mecanismos necessitam de melhorias pela alta administração.

Além desta introdução, este artigo está estruturado em mais 4 (quatro) seções. A segunda seção discute a fundamentação teórica. Conceitos como a Teoria da Agência, Governança Corporativa, Governança Pública e Governança de TI são debatidos no sentido de questionar ou responder aos resultados encontrados. A terceira seção apresenta a metodologia utilizada, com a apresentação do lócus e do modelo de coleta e análise de dados. A quarta seção, os resultados e discussão. Nesta parte serão apresentados os dados obtidos nos questionários e pesquisa documental, com suas devidas interpretações. E na quinta, e última seção, são apresentadas as conclusões da pesquisa.

\section{FUNDAMENTAÇÃO TEÓRICA}

O trabalho está baseado na Teoria da Agência, Governança Corporativa, Governança Pública e Governança em Tecnologia da Informação, apresentados nas seções seguintes.

\subsection{Teoria da Agência}

A Teoria da Agência tem por objetivo explicar as relações que existem entre os indivíduos que possuem a propriedade e os que possuem o controle das organizações. Os indivíduos com propriedade são reconhecidos como principal, enquanto que os que têm o controle, como agente. 0 principal tem por função manter financeiramente a organização, definir princípios e avaliar as informações, enquanto que o agente é remunerado para tomar decisões e conduzir a execução dos processos da organização levando em consideração os interesses do principal (ARRUDA; MADRUGA; FREITAS JUNIOR, 2008).

Os problemas de agência fundamentam-se na questão da informação assimétrica, que surge em decorrência dos diferentes níveis de informação que existem entre 0 agente e o principal. Como o principal delega poder e autoridade ao agente, este possui mais informações sobre a organização do que o próprio principal. Neste cenário, 0 agente pode usar estas informações não para o benefício da organização, mas para atender ao seu próprio interesse (SEGATTO-MENDES; ROCHA, 2005). Dos conflitos de interesses entre as partes interessadas (agente e principal) devido a assimetria informacional, que se apresenta tanto no setor privado, quanto no público, surgiu a necessidade de criar princípios e regras que levassem em consideração o acompanhamento das ações realizadas pelos agentes para o interesse do principal (ALTOUNIAN; SOUZA; LAPA, 2017). A administração das organizações a partir de princípios e regras que protegem as partes interessadas é o que se entende por Governança Corporativa.

\subsection{Governança Corporativa}

A governança corporativa é composta por um conjunto de princípios e mecanismos que governam os processos decisórios de uma organização. Neste sentido, ela é bastante útil em organizações com processos decisórios que se destinam a dirigir e atingir a prestação de contas (MARQUES, 2007). De acordo com o Instituto Brasileiro de Governança Corporativa (IBGC) (2017), a governança corporativa é definida como:

[...] o sistema pelo qual as empresas e demais organizações são dirigidas, monitoradas e incentivadas, envolvendo os relacionamentos entre sócios, conselho de administração, diretoria, órgãos de fiscalização e controle, e demais partes interessadas. (IBGC, 2017).

Segundo Weill e Ross (2006), uma boa governança corporativa é importante para os investidores profissionais. As organizações que possuem um bom sistema de governança corporativa são organizações 
com maior credibilidade no mercado e têm maiores chances de superar crises econômicas. Com o objetivo de não correr riscos financeiros, os acionistas preferem investir em organizações que adotam os melhores modelos de governança corporativa. Segundo Borges e Serrão (2005), a eficiência de um modelo de governança corporativa depende do alinhamento com a cultura local de um país. Neste sentido, o sistema de governança corporativa precisa estar estruturado de acordo com as particularidades de cada país e adotar um código de melhores práticas que leve em consideração o ambiente de sua aplicação (IBGC, 2017).

Com o objetivo de adotar as melhores práticas de administração, as organizações públicas vêm incorporando a governança corporativa do setor privado. 0 objetivo das organizações públicas é entregar para a sociedade um serviço de qualidade que atenda aos anseios da população. É nesse contexto que os modelos organizacionais de gestão pública vêm evoluindo no sentido de resolver os conflitos de interesses e incentivar questões como sustentabilidade financeira e transparência na gestão.

\subsection{Governança Pública}

A incorporação de práticas de governança corporativa das organizações privadas nas organizações públicas teve como objetivo melhorar os padrões de atendimento nestas organizações (BOVAIRD, 2005). Como os objetivos das organizações públicas são diferentes das organizações privadas, algumas práticas de governança corporativa foram adaptadas, e outras criadas para o contexto daquelas organizações. De acordo com Bovaird (2005), o aperfeiçoamento das práticas de governança corporativa nas organizações públicas contribuiu para a melhoria dos processos nos diferentes contextos organizacionais. Segundo o autor supracitado, os seguintes princípios são aplicados tanto nas organizações públicas, quanto privadas: tomada de decisão democrática, engajamento das partes interessadas, tratamento justo e honesto dos cidadãos, sustentabilidade das políticas, disposição e capacidade de trabalhar em parceria, transparência, prestação de contas, inclusão social e igualdade (de oportunidade, de uso, de custo, de acesso ou de resultados), respeito pela diversidade, respeito pelos direitos dos outros, respeito pelo Estado de Direito e capacidade de competir em um ambiente global.

Foi no contexto de mitigar os conflitos de interesses existentes entre a sociedade (o principal) e os gestores públicos (agente) que emergiram as principais definições de governança pública encontradas na literatura.

Bovaird e Löffler (2003) entendem por governança pública a interação que existe entre as partes interessadas para influenciar os resultados das políticas públicas. Maddalena (2006), ao realizar uma compilação de várias definições de governança pública, a define como um processo pelo qual um grupo de indivíduos de uma organização recebe autoridade para agir em nome de uma população maior para tomar decisões sobre o bem-estar da organização, e para ser responsabilizado por suas decisões. Dentro de uma perspectiva de orientação e controle, o TCU (2014) definiu governança pública como:

[...] um conjunto de mecanismos de liderança, estratégia e controle postos em prática para avaliar direcionar e monitorar a gestão, com vistas à condução de políticas públicas e à prestação de serviços de interesse da sociedade (TCU, 2014).

As definições de governança pública nos mostram a importante relação que deve existir entre a sociedade, maior interessada nos serviços públicos, e os gestores públicos, denominado agente dos recursos públicos, principal ator na gestão dos serviços públicos. Desta relação existente entre a sociedade (principal) e os gestores públicos (agentes), Maddalena (2006) lembra que a participação da sociedade na tomada de decisões é cada vez mais vista como uma característica essencial para o sistema de governança pública.

Para os gestores públicos exercerem suas funções de avaliar as necessidades das partes interessadas, direcionar os recursos disponíveis, e monitorar o seu uso no sentido de fazer o melhor aproveitamento, é necessário adotar a liderança, estratégia e controle como mecanismos de governança (TCU, 2014). De acordo o TCU (2014), o mecanismo de liderança é descrito como: 
[...] conjunto de práticas, de natureza humana ou comportamental, que assegura a existência das condições mínimas para o exercício da boa governança, quais sejam: pessoas íntegras, capacitadas, competentes, responsáveis e motivadas ocupando os principais cargos das organizações e liderando os processos de trabalho (TCU, 2014).

O mecanismo de estratégia refere-se a um conjunto de práticas executadas pela liderança organizacional no sentido de garantir que os objetivos de alto nível da organização reflitam-se em ações de gestão nos níveis subalternos. Esse conjunto de práticas exercido pela liderança tem como ponto de partida: a visão de futuro da organização; missão institucional; e análise dos ambientes interno e externo (TCU, 2014).

Não menos importante, o mecanismo de controle é responsável por realizar revisões dos mecanismos de liderança e estratégia com o objetivo de sugerir melhorias. Neste sentido, serve para alinhar os resultados produzidos pelos outros mecanismos aos interesses das partes interessadas.

Cada mecanismo de forma isolada não produz os resultados esperados para as partes interessadas (TCU, 2014). Percebe-se que entre os mecanismos, o de liderança exige prioridade quanto a sua implementação no sistema de governança. Este é importante não somente no sentido de entender e prio rizar as necessidades das partes interessadas, mas também de conduzir a implementação dos mecanismos de estratégia e controle.

\subsection{Governança de Tecnologia da Informação}

A informação e a TI formam a base dos processos organizacionais. Tendo em vista a importância do tratamento da informação, os processos de aquisição e desenvolvimento de novas soluções em TI sugerem que sejam discutidos entre as unidades de negócios e de TI das organizações. Segundo Weill e Ross (2006, p. 2), "extrair maior valor da TI é uma competência organizacional de importância crescente". De acordo com os autores, todos os líderes nas organizações precisam desenvolver esse tipo de competência.

A partir do momento que os processos organizacionais começaram a ser assistidos por tecnologias da informação, muitos acadêmicos e profissionais preocuparam-se em estudar as relações entre causas e efeitos do uso da TI para a realização dos objetivos organizacionais (VAN GREMBERGER, 2004). Essas pesquisas foram importantes e contribuíram para uma variedade de definições de governança de $\mathrm{Tl}$ que encontramos atualmente na literatura.

De acordo com Weill e Ross (2006), a governança de TI é definida como "a especificação dos direitos decisórios e do framework de responsabilidades para estimular comportamentos desejáveis na utilização da TI". A ABNT NBR ISO/IEC 38500, a define como "o sistema pelo qual o uso atual e futuro da TI é dirigido e controlado" (ABNT, 2009, p. 3). Segundo a Norma, a governança corporativa de TI significa "avaliar e direcionar o uso da TI para dar suporte à organização e monitorar seu uso para realizar os planos. Inclui a estratégia e as políticas de uso da TI dentro da organização" (ABNT, 2009, p. 3).

Para Van Gremberger (2004), a governança de TI consiste nas estruturas organizacionais e processos de liderança que assegurem que a TI sustente as estratégias organizacionais. Nesta e nas demais definições de governanças de TI é comum e implícita a ideia do elo existente entre a Tl e os processos de negócios presentes e futuros nas organizações (VAN GREMBERGER, 2004). Neste sentido, a interdependência entre área de negócio e de TI exige a presença de uma liderança organizacional para conduzir as relações e fazer com que os objetivos corporativos sejam alcançados (WEILL; ROSS, 2006, p. 7).

Da estreita relação que existe entre a TI e os processos de negócios, e, de como a TI pode gerar valor para a organização, é importante apresentar, de forma conceitual, a diferença entre governança de $\mathrm{Tl}$ e gerenciamento de Tl. $\mathrm{O}$ gerenciamento de TI consiste na entrega efetiva de serviços e produtos de TI e no gerenciamento das atuais operações de TI. A Governança de TI, por sua vez, é um conceito mais amplo e concentra-se, de forma estratégica, em usar a TI para atender às demandas atuais e futuras do negócio e dos clientes das organizações (VAN GREMBERGER, 2004). 


\subsubsection{Governança de TI nas Universidades Públicas Federais}

De acordo com o TCU (2014), a implementação da governança de Tl em órgãos e entidades da APF tem por finalidade assegurar que o dinheiro público está sendo bem aplicado, assim como contribuir para que essas organizações atinjam seus objetivos através do alinhamento entre TI e negócio. As universidades públicas federais fazem parte da APF e são instituições que têm por objetivo promover ensino, pesquisa e extensão, sendo a sociedade a principal beneficiada desses serviços. Nestas instituições, a TI desempenha um papel significativo, vez que está inserida em um ambiente de produção de informação e conhecimento. A disponibilidade de sistemas cada vez mais robustos têm acabado com os procedimentos manuais. Hoje, de forma virtual, é possível realizar matrícula, emitir histórico, tramitar processos, entre outras funcionalidades de um sistema de gestão acadêmica.

De acordo com Putz (2015), diferentemente do setor privado, as universidades públicas federais com escassos recursos governamentais e pessoal pouco qualificado em novas tecnologias possuem um processo de inovação tecnológica mais lento que o setor privado. Para a autora, o "cenário é preocupante e contraditório uma vez que o próprio objeto de trabalho da universidade é a informação e o conhecimento." (PUTZ, 2015, p. 65). Diante deste cenário, como fazer com que a TI nestas organizações realize os benefícios esperados pela sociedade, principal interessada nos serviços prestados? Esta é uma questão que tem exigido do TCU avaliações e auditorias no sentido de promover a governança de TI.

\subsubsection{Control Objectives for Information and Related Technologies (COBIT)}

O COBIT é um modelo de governança e gestão de TI, desenvolvido e difundido pela Information System Audit and Control Association (ISACA), que tem por função criar valor por meio da Tl, "mantendo o equilíbrio entre a realização de benefícios e a otimização dos níveis de risco e de utilização dos recursos" (ISACA, 2012, p. 15). Por ser um modelo genérico e de fácil integração com outros padrões do mercado, pode ser utilizado por organizações públicas ou privadas de todos os portes e com diversos objetivos de negócios.

O COBIT 5 (versão divulgada em 2012) é baseado em cinco princípios básicos que, juntos, permitem que qualquer organização implemente a governança e gestão de TI de forma eficiente. Os cinco princípios do COBIT 5 são: 1 - Satisfazer necessidades das partes interessadas; 2 - Cobrir a organização de ponta a ponta; 3 - Aplicar um framework integrado e único; 4 - Possibilitar uma visão holística; 5 - Separar governança do gerenciamento.

Além dos 5 (cinto) princípios, o COBIT 5 fornece 7 (sete) habilitadores que são mecanismos adotados pelas organizações para fazer com que os objetivos de TI sejam alcançados. Entendidas as necessidades de negócios e definidos os objetivos corporativos, a organização define dentro das sete categorias de habilitadores os necessários para fazer com que a TI gere valor ao negócio. As 7 (sete) categorias de habilitadores são definidas pelo COBIT 5 como:

Princípios, políticas e modelos são veículos para a tradução do comportamento desejado em orientações práticas para a gestão diária.

Processos descrevem um conjunto organizado de práticas e atividades para o atingimento de determinados objetivos e produzem um conjunto de resultados em apoio ao atingimento geral dos objetivos de TI.

Estruturas organizacionais são as principais entidades de tomada de decisão de uma organização. Cultura, ética e comportamento das pessoas e da organização são muitas vezes subestimados como um fator de sucesso nas atividades de governança e gestão.

Informação permeia qualquer organização e inclui todas as informações produzidas e usadas pela organização. A Informação é necessária para manter a organização em funcionamento e bem governada, mas no nível operacional, a informação por si só é muitas vezes o principal produto da organização.

Serviços, infraestrutura e aplicativos incluem a infraestrutura, a tecnologia e os aplicativos que fornecem à organização o processamento e os serviços de tecnologia da informação. 
Pessoas, habilidades e competências estão associadas às pessoas e são necessárias para a conclusão bem-sucedida de todas as atividades bem como para a tomada de decisões corretas e tomada de medidas corretivas. (ISACA, 2012, p.29)

\section{METODOLOGIA}

A pesquisa foi desenvolvida na Universidade Federal do Recôncavo da Bahia (UFRB), instituição localizada na cidade de Cruz das Almas, Bahia, Brasil. De acordo com a Comissão Própria de Avaliação (CPA), em 2016, na média dos dois semestres do ano, a UFRB contava com um total de 9.005 alunos matriculados, sendo 8.883 alunos ativos na graduação e 122 alunos ingressos na pós-graduação. De acordo com a CPA, 0 quadro de professores na instituição, naquele ano, era de 844 docentes, sendo 763 efetivos e 81 substitutos. No que tange o número de funcionários, a universidade tinha 1.196, sendo 715 técnicos administrativos e 481 terceirizados. A Coordenadoria de Tecnologia da Informação (COTEC) é a instância da UFRB responsável pela gestão da TI. Atualmente está subordinada à Pró-Reitoria de Planejamento e possui 4 (quatro) núcleos. 0 Figura 1 apresenta a estrutura organizacional de TI da UFRB.

Figura 1 - Estrutura organizacional de TI

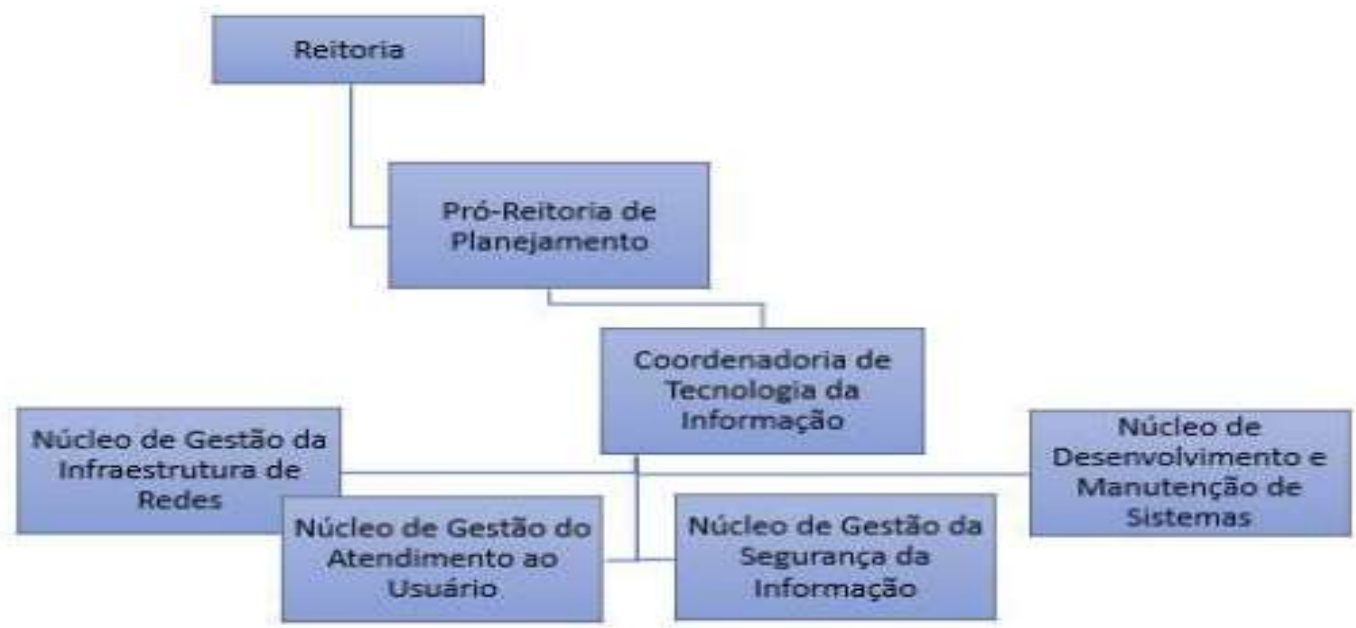

Fonte: Adaptado pelo autor, com base no relatório de autoavaliação institucional (2015-2017)

Como o tema governança de TI relaciona-se com as atividades estratégicas da instituição, decidiu-se incluir no universo da pesquisa 22 (vinte e dois) tomadores de decisão de nível estratégico que influenciam nas principais decisões de TI. A partir da participação desses tomadores de decisão na pesquisa, no que tange a percepção da implementação dos mecanismos de governança de TI, juntamente com a análise documental, identificou-se quais os mecanismos de governança de TI necessitam de maior atenção pela alta administração acerca do processo de implementação. Participaram da pesquisa: 7 (sete) Pró-Reitores; 7 (sete) Diretores de Centros; 2 (dois) Assessores; 5 (cinco) Superintendentes e 1 (um) Auditor Interno.

Para o contexto desta pesquisa, convencionou-se chamar as 7 (sete) categorias de habilitadores do COBIT 5 de categorias de mecanismos de governança de TI, propondo para cada categoria um conteúdo para direcionar a coleta e análise dos dados. 0 Quadro 1 apresenta as categorias de mecanismos do COBIT 5 com os conteúdos que direcionaram a construção do questionário e a análise documental. 
Quadro 1 - Modelo proposto para estudar a implementação dos mecanismos de governança de TI na UFRB

\begin{tabular}{|l|l|}
\hline \multicolumn{1}{|c|}{ Mecanismos } & \multicolumn{1}{c|}{ Conteúdo } \\
\hline Estrutura Organizacional & Atuação das estruturas de tomada de decisão de TI. \\
\hline $\begin{array}{l}\text { Princípios, políticas e } \\
\text { modelos }\end{array}$ & $\begin{array}{l}\text { Princípios, políticas e modelos como mecanismos de alinhamento } \\
\text { estratégico. }\end{array}$ \\
\hline Informação & Qualidade das informações produzidas pelos aplicativos de software. \\
\hline $\begin{array}{l}\text { Serviços, infraestrutura e } \\
\text { aplicações }\end{array}$ & $\begin{array}{l}\text { Utilidade e garantia de serviços, infraestrutura e aplicativos de TI às } \\
\text { necessidades de negócio. }\end{array}$ \\
\hline Processos & Satisfação da área de negócio com os processos de gestão de TI. \\
\hline $\begin{array}{l}\text { Cultura, ética e } \\
\text { comportamento }\end{array}$ & Mecanismos de controle para evitar conflitos de interesses nas decisões de TI. \\
\hline $\begin{array}{l}\text { Pessoas, habilidades e } \\
\text { competência }\end{array}$ & Habilidade e competência dos servidores técnicos e analistas de TI. \\
\hline
\end{tabular}

Fonte: Elaborado pelos autores, com base nos habilitadores do COBIT 5 (2017).

No que tange aos aspectos da estrutura do questionário, a versão final apresentada aos respondentes constou de vinte e quatro questões. Todas as questões foram extraídas dos conteúdos relacionadas aos mecanismos do COBIT 5. 0 questionário ficou aberto entre os meses de junho e agosto de 2017, período em que foram obtidas todas as respostas dos tomadores de decisão. 0 tempo estimado para a realização do questionário foi de vinte minutos. Junto ao questionário, solicitou que o respondente informasse seu e-mail para que o pesquisador pudesse monitorar as respostas e enviar lembrete, solicitando somente aos que não responderam.

Após a aplicação do questionário aos 22 (vinte e dois) tomadores de decisão, que teve o objetivo de identificar a percepção quanto à implementação dos mecanismos de governança de $\mathrm{Tl}$, realizou-se uma pesquisa documental a fim de melhorar a interpretação do resultado da pesquisa de campo. No sentido de direcionar a pesquisa documental e obter os dados primários, inicialmente, realizou-se a análise do Plano de Desenvolvimento Institucional 2015-2019, dos relatórios de gestão de 2015 e 2016, do relatório de autoavaliação institucional 2015-2017 e no site da instituição. A consulta a outros documentos, como Portarias e Resoluções, foi realizada até o mês de agosto de 2017, período em que se encerrou a consulta aos documentos e começou a análise e interpretação dos mesmos. A consulta aos documentos foi direcionada tendo por base o modelo proposto para estudar a implementação dos mecanismos de governança de TI na UFRB conforme Quadro 1.

Após a fase de coleta de dados através do uso de questionário, iniciou-se a fase de análise e interpretação do material coletado. Com o objetivo de indicar o grau de atitude dos sujeitos pesquisados em relação ao objeto de estudo, utilizou-se no questionário a escala Likert de cinco pontos. Este método consiste em "um conjunto de itens apresentados como afirmações ou opiniões, para os quais se pede a reação dos participantes" em relação ao objeto investigado (SAMPIERI; COLLADO; LUCIO, 2013, p. 261). A escala utilizada obteve os seguintes graus de atitude em relação as questões apresentadas aos tomadores de decisão: sempre; na maioria das vezes sim; algumas fez sim, algumas vezes não; na maioria das vezes não, nunca.

Para analisar as questões, utilizou-se o cálculo do ranking médio (RM) proposto por Oliveira (2005), que é obtido através da relação entre a média ponderada (MP), e o número de sujeitos (NS) que opinaram na questão. Assim, $\mathrm{RM}=\mathrm{MP} / \mathrm{NS}$, onde $\mathrm{MP}=\Sigma\left(\mathrm{fi}^{*} \mathrm{v} \mathrm{l}\right), \mathrm{NS}=\mathrm{n}^{\circ}$. de sujeitos, $\mathrm{fi}=$ frequência de cada resposta em cada item, $\mathrm{vl}=$ valor de cada item .

Como as questões foram agrupadas por conteúdo, analisou-se tanto o RM para cada questão como para cada conteúdo. Usou-se o seguinte critério para análise das questões e dos conteúdos: os valores 
encontrados menores que 3 (três) foram considerados com atitude negativa, e maiores que 3 foram considerados com atitude positiva, considerando a escala de 5 (cinco) pontos. Para os valores iguais a 3 , considerou-se que os sujeitos não têm opinião definida, sendo neste caso um ponto neutro da escala. A partir dos resultados obtidos, interpretou-se a opinião dos principais tomadores de decisão no que tange a implementação dos mecanismos de governança de TI na instituição.

\section{RESULTADOS E DISCUSSÃO}

Os resultados da pesquisa indicaram que os tomadores de decisão da instituição tiveram uma percepção negativa em relação a atuação do Comitê de Governança Digital (CGD) (ranking médio de 2,77), e ao Comitê de Segurança da Informação (CSIC) (ranking médio de 2,95). No que tange às ações de TI desenvolvidas pela Coordenadoria de Tecnologia da Informação (COTEC), os tomadores de decisão tiveram uma percepção extremamente positiva (ranking médio de 4,05). Considerando as 3 (três) estruturas de tomada de decisão de TI na instituição, 2 (duas) com atribuições estratégicas (CGD e CSIC), e 1 (uma) com atribuições táticas e operacionais (COTEC), a média do ranking médio foi de 3,26, indicando uma percepção positiva dos tomadores de decisão.

\subsection{Atuação das estruturas organizacionais de tomada de decisão de TI}

Percebe-se que a atitude positiva dos tomadores de decisão está na estrutura organizacional de TI responsável por decisões táticas e operacionais. Em um trabalho realizado por Silva (2016) sobre a contribuição da TI para as práticas de gestão estratégica da UFRB, o autor encontrou a mesma percepção desses tomadores de decisão no que tange a esta estrutura de TI. De acordo com o autor, os tomadores de decisão avaliaram como positivamente o suporte prestado pela COTEC. Estes resultados revelam que a COTEC tem se tornado uma instância de referência acerca do tratamento das demandas de TI da instituição, principalmente porque tem dado suporte à implantação de um Sistema Integrado de Gestão (SIG), e demandas de infraestrutura e suporte aos usuários.

A análise realizada acerca da percepção negativa dos tomadores de decisão no que tange às instâncias responsáveis por tomada de decisão estratégica (CGD e CSIC), assim como a ausência de evidências documentais na instituição de que estas instâncias têm atuado, revela que estes comitês não têm cumprido com suas atribuições dentro do sistema de governança de TI da instituição.

Uma das áreas foco da governança de TI é realizar o alinhamento estratégico entre a TI e as áreas de negócio. Observando a percepção dos tomadores de decisão da UFRB acerca dos 2 (dois) comitês (CGD e CSIC), a ausência de evidências documentais (atas de reuniões), e levando em consideração as implicações encontradas em um trabalho realizado por Putz (2015), de que a ausência de alinhamento estratégico está relacionada a consolidação dos comitês de TI, pode-se inferir que na UFRB a não atuação destas estruturas de tomada de decisão estratégica está comprometendo o alinhamento estratégico da universidade.

\subsection{Princípios, políticas e modelos de TI como mecanismos de alinhamento estratégico}

A investigação a partir desse mecanismo de governança de TI deu-se por meio de três questões que tiveram como objetivo indicar o nível de alinhamento estratégico a partir dos princípios e políticas da instituição pesquisada. Com a intenção de mensurar o nível de alinhamento da área de negócio com esta categoria de mecanismo, questionou-se sobre a percepção dos tomadores de decisão acerca da participação ou influência destes na formulação ou atualização dos princípios, políticas e modelos de TI. Acerca do processo de comunicação deste mecanismo para a área de negócio, quando concebidos e implementados na universidade, e sobre o nível de alinhamento dessa categoria de mecanismo com as atividades desempenhadas pelos tomadores de decisão. 
A percepção positiva dos tomadores de decisão concentrou-se na questão que tratou do alinhamento das atividades dos seus setores com os princípios, políticas e modelos de TI (ranking médio 3,59), assim como na questão que tratou da comunicação da concepção, implementação e atualização desse mecanismo pelos órgãos de governança de $\mathrm{TI}$ (ranking médio 3,09). Com relação à participação ou influência dos tomadores de decisão na construção dos princípios, políticas e modelos de TI, a percepção foi negativa (ranking médio 2,36), indicando que a maioria dos tomadores de decisão não são consultados para a construção destes que formam uma categoria de mecanismo de governança de TI responsável por conceber as regras da organização, atuando na transmissão de instruções e orientações necessárias para o bom funcionamento da governança de TI na universidade.

Da análise documental realizada, com exceção da existência da Políticas de Segurança da Informação e Comunicação - POSIC da UFRB, não foram encontrados quaisquer documentos com declaração de princípios e políticas de TI na instituição. Logo, percebe-se uma contradição entre a percepção positiva desses tomadores de decisão em relação a este mecanismo e a ausência de documentos que comprovem este alinhamento estratégico.

Ao analisar o Plano de Desenvolvimento Institucional 2015-2019 da UFRB, observou-se metas relacionadas à TI para ampliar e melhorar a infraestrutura física e administrativa da instituição no que tange a área de gestão (UFRB, 2015, p. 120). Entretanto, apesar das metas de TI estarem declaradas para atingir os objetivos corporativos da instituição, demonstrando um ponto de origem para o desenvolvimento de estratégias de TI, não existe um Planejamento Estratégico de Tecnologia da Informação (PETI), documento que expressa os princípios de TI que sustentam os objetivos corporativos.

Levando em consideração a afirmação de Nascimento (2014) de que o PETI "é o documento que serve de ligação para o estabelecimento do Alinhamento Estratégico no Plano Geral da Organização representado pelo Planejamento Estratégico Institucional, sendo este o responsável pelas diretrizes gerais de toda organização (NASCIMENTO, 2014, p. 13)", pode-se afirmar que com a inexistência de um PETI na UFRB, não está ocorrendo alinhamento estratégico da TI com as áreas de negócio.

\subsection{Qualidade das informações produzidas pelos sistemas automatizados}

A percepção positiva dos tomadores de decisão (ranking médio de 3,18 ) deu-se para a qualidade contextual da informação, uma vez que os tomadores de decisão percebem as informações como aplicáveis e úteis para as atividades de gestão. Enquanto que a percepção negativa (ranking médio de 2,45 ) deu-se para a qualidade intrínseca dessas informações, tendo em vista que os tomadores de decisão não percebem as informações em conformidade com os valores reais e efetivos da área de negócio. Este resultado negativo é preocupante visto que essas informações estão sendo usadas por áreas estratégicas de uma instituição que trabalha com ensino, pesquisa e extensão, e que precisa de informações sempre em conformidade com os valores reais e efetivos disponíveis para a comunidade acadêmica.

Como a UFRB passa por um processo de implantação do Sistema Integrado do Gestão (SIG), o ranking médio negativo para a qualidade intrínseca das informações produzidas pelos sistemas automatizados sugere problemas nos processos de validações de migrações de dados a partir de sistemas legados, assim como de capacitação de servidores para a manutenção desses novos sistemas. Segundo o relatório de gestão do exercício de 2016, estes processos ocorreram, principalmente, na finalização da implantação do Sistema Integrado de Gestão Acadêmica (SIGAA), conforme observado:

[...] no exercício de 2016 finalizamos a implantação do Sistema Integrado de Gestão Acadêmica (SIGAA). $\mathrm{Na}$ condição de gestores do negócio, fomos requisitados pela administração central a compor comissão de implantação que foi organizada em três etapas, a saber: homologação dos roteiros de dados, validação da migração dos dados e capacitação de servidores para o uso do sistema. A expectativa com o uso deste sistema integrado é que tenhamos um grande avanço da gestão acadêmica em todos os setores. (UFRB, 2017, p. 33-34) 


\subsection{Habilidade e competência dos servidores técnicos e analistas de TI}

A percepção dos tomadores de decisão acerca das habilidades e competências do quadro de servidores de TI da UFRB foi positiva (ranking médio de 3,73). Esta percepção está relacionada à satisfação dos tomadores de decisão com o desempenho dos servidores de TI, que por sua vez são os responsáveis por executar as ações planejadas da Tl.

Com o objetivo de validar a percepção positiva dos tomadores de decisão acerca desta categoria de mecanismos na instituição, procurou-se nos documentos institucionais evidências que justificassem tal percepção. Ao consultar o relatório de gestão do exercício de 2015 e 2016, observou-se que foram oferecidos os seguintes cursos pela instituição: Ponto de função, IPv6, Segurança de Redes, Segurança de Redes sem fio. Consta no relatório do ano de 2016 que, ao término do contrato com a empresa licenciada (ESIG Software \& Consultoria), realizou-se transferência de tecnologia da contratada para a contratante (UFRB).

A percepção positiva dos tomado res de decisão acerca das habilidades e competências do quadro de servidores de TI sugere que, para além dos cursos oferecidos oriundos de demandas específicas, os servidores de TI realizam capacitações por conta própria. Devido à ausência de definições de princípios, políticas e modelos de TI, assim como de evidências de atuação das estruturas de tomada de decisão estratégicas de TI no que se refere a análise do quadro de pessoal de TI, as capacitações e qualificações dos analistas e técnicos de TI podem estar ocorrendo de forma desalinhada ao planejamento estratégico da universidade.

\subsection{Utilidade e garantia dos serviços, infraestrutura e aplicativos de TI para as necessidades de negócios}

Para as questões que abordaram aspectos relacionados a utilidade, os tomadores de decisão tiveram uma percepção positiva (média do ranking médio 3,67). As questões buscaram identificar a utilidade dos serviços disponíveis no catálogo de serviços de $\mathrm{TI}$, dos softwares desenvolvidos ou adquiridos para as necessidades da instituição e dos recursos de TI utilizados para tratamento das informações do setor investigado. Cabe destacar que $77 \%$ dos tomadores de decisão tiveram uma percepção positiva em relação aos softwares desenvolvidos ou adquiridos para seus setores como soluções estratégicas. No trabalho realizado por Silva (2016), o autor havia diagnosticado que as áreas estratégicas da UFRB acreditavam que a implantação do Sistema Integrado de Gestão (SIG) permitiria uma melhoria tanto da área de negócio quanto da área de TI. Estes resultados apontam para um amadurecimento dos tomadores de decisão acerca da importância da automatização dos processos através do SIG, o que sugere existir na UFRB uma cultura por parte dos tomadores de decisão de abertura a soluções automatizadas.

As perguntas relacionadas a garantia envolveram aspectos como prejuízo das atividades devido as interrupções nos serviços, tempo médio para tratar as solicitações de um serviço de TI, bem como o quão 0 acesso à internet atende as atividades do setor. Para este aspecto, os resultados da pesquisa apontaram que os tomadores de decisão tiveram uma percepção negativa (média do ranking médio 2,48).

Os resultados da investigação desta categoria de mecanismos sinalizam que a instituição cumpre com o que o usuário espera em termos de serviços, entretanto não tem cumprido com as garantias de entrega. Este resultado indica que a instituição está com a sua capacidade de serviços de TI comprometida, visto que os aplicativos e infraestrutura de TI disponíveis na instituição depende de eficiência na prestação de serviços de TI. Dessa forma, a percepção negativa dos tomadores de decisão acerca da garantia revela que a entrega de valor, objetivo do modelo COBIT 5 e da governança de TI, está prejudicada, e, portanto, não atendendo as partes interessadas do negócio.

\subsection{Mecanismos de controle para evitar conflitos de interesses nas decisões de TI}

A análise acerca da categoria de mecanismo cultura, ética e comportamento teve o objetivo de identificar o compromisso da instituição em incentivar e manter comportamentos éticos dos membros da alta 
administração acerca das decisões de TI. Neste sentido, perguntou-se aos tomadores de decisão da instituição acerca da frequência com que a instituição implementa mecanismos de controle para evitar vieses, preconceitos ou conflitos de interesse que influenciem nas decisões de TI por membros da alta administração. A percepção dos tomadores de decisão foi negativa (ranking médio 2,86).

A percepção negativa dos tomadores de decisão acerca da implementação de mecanismos de controle que evitam conflitos de interesses na tomada de decisão de TI se alinha a ausência de princípios e políticas de TI como mecanismos de comunicação dos valores corporativos e comportamentos desejáveis na instituição. A implementação de mecanismos de controle como este, passa pela elaboração de normas alinhadas aos princípios corporativos, que forneçam orientação sobre o comportamento organizacional desejado no que tange ao processo de tomada de decisão de TI.

\subsection{Satisfação da área de negócio com os processos de gestão de TI}

A inspiração para a construção das questões acerca da categoria de mecanismos processos deu-se a partir da observação das atividades desenvolvidas nos 4 (quatro) núcleos da COTEC (Núcleo de Gestão do Atendimento ao Usuário; Núcleo Gestão da Infraestrutura de Redes; Núcleo de Gestão da Segurança de Informação e Núcleo de Desenvolvimento e Manutenção de Sistemas), relacionando-as com 3 (três) processos do COBIT 5, a saber: DSS01 Gerenciar Operações, DSS05 Gerenciar Serviços de Segurança, e BAI03 Gerenciar a Identificação e Desenvolvimento de Soluções.

Da análise realizada, observa-se que os tomadores de decisão tiveram uma percepção positiva dos processos de gestão de $\mathrm{TI}$ (média do ranking médio de 3,25) que envolvem serviços de segurança, desenvolvimento de software e gerenciamento de operações. Este resultado demonstra a satisfação dos tomadores de decisão com os processos de gestão de $\mathrm{Tl}$, e corrobora o encontrado sobre a atuação operacional da COTEC na instituição, avaliada pelos tomadores de decisão como positiva.

Apesar da percepção positiva acerca dos indicadores relacionados aos processos de gestão de $\mathrm{Tl}$, a ausência de um PETI na instituição sugere processos desvinculados de metas corporativas, e, portanto, com execução sem alinhamento estratégico.

\section{CONCLUSÕES}

A análise realizada indicou que a implementação dos mecanismos de governança de TI na UFRB no período analisado encontrava-se em um estágio embrionário. Constatou-se inércia das estruturas de tomada de decisão estratégica de TI (CGD e CSIC), e ausência da definição de princípios, políticas e modelos de TI, que, conforme o COBIT 5 são fundamentais para a implementação das demais categorias de mecanismos. A constatação acerca do estágio embrionário da implementação dos mecanismos de governança de TI permite concluir ausência de alinhamento estratégico entre Tl e negócio, o que implica no comprometimento da entrega de valor proporcionado pela TI para a comunidade acadêmica.

A UFRB atua na indissociabilidade do Ensino-Pesquisa-Extensao, por isso seu objetivo maior é atuar no tripé Ensino, Pesquisa e Extensão. Neste sentido, necessita de informações de qualidade para a tomada de decisão dos gestores deste tripé. Constatou-se com a investigação que a universidade precisa melhorar seus processos de implantação de sistemas de informações, com treinamentos de usuários, validação de migração de carga de dados a partir de sistemas legados, bem como planos de capacitação para analistas e técnicos de TI.

Percebeu-se com a pesquisa, um amadurecimento dos tomadores de decisão acerca da importância da automatização dos processos através do Sistema Integrado de Gestão (SIG), o que sugere existir na UFRB uma cultura, por parte dos tomadores de decisão, de abertura a soluções automatizadas. Entretanto, para a categoria de mecanismo que trata de questões relacionadas ao comportamento desejado dentro da instituição, não foram encontradas evidências que tratassem do controle de conflitos de interesses nas decisões institucionais de TI. 
Quanto a capacidade de serviços de $\mathrm{TI}$, a pesquisa revelou que carece de melhorias, visto que os aplicativos e infraestrutura de TI disponíveis na instituição dependem de eficiência na prestação de serviços de TI, o que foi percebida de forma negativa pelos tomadores de decisão. Essas melhorias passam pela implantação de um sistema de gerenciamento de serviços, com implantação do catálogo de serviços, acordos de nível de serviços e capacidade de serviços.

De acordo com a ISACA (2012), os objetivos corporativos estão vinculados a objetivos de TI (definidos no PETI), que por sua vez estão vinculadas às metas dos mecanismos de governança de TI (habilitadores do COBIT 5). No que tange aos processos de gestão $\mathrm{Tl}$, percebeu-se que estão desvinculados de metas corporativas devido à ausência de um PETI, e, portanto, sendo executados sem alinhamento estratégico. Segundo Nascimento (2014), o PETI é o documento responsável por definir as diretrizes da TI alinhadas as diretrizes gerais de toda a organização que são definidas no Planejamento Estratégico Institucional.

\section{REFERÊNCIAS}

ALTOUNIAN, Cláudio Sarian; SOUZA, Daniel Santos; LAPA, Leonard Renne Guimarães. Gestão e governança pública para resultados: uma visão prática. Belo Horizonte: Fórum, 2017.

ARRUDA, Giovana Silva de; MADRUGA, Sérgio Rossi; FREITAS JUNIOR, Ney Izaguirry de. A Governança corporativa e a teoria da agência em consonância com a controladoria. Revista de Administração da UFSM, Santa Maria, v. 1, n. 1, p. 71-84, jan./abr. 2008.

ASSOCIAÇÃO BRASILEIRA DE NORMAS TÉCNICAS (ABNT). NBR ISO/IEC 38500: governança corporativa de tecnologia da informação. Rio de Janeiro: ABNT, 2009.

BORGES, Luiz Ferreira Xavier; SERRÃO, Carlos Fernando de Barros. Aspectos de governança corporativa moderna no Brasil. Revista do BNDES, Rio De Janeiro, v. 12, n. 24, p. 111-148, dez. 2005.

BOVAIRD, Tony. Public governance: Balancing stakeholder power in a network society. International Review of Administrative Sciences, v. 71, n. 2, p. 217-228, 2005.

BOVAIRD, Tony; LÖFFLER, Elke. Evaluating the quality of public governance: indicators, models and methodologies. International Review of Administrative Sciences, v. 69, n. 3, p. 313-328, 2003.

CAVALCANTI FILHO, J osé Hermano. Investigação da influência da governança de TI nas instituições federais de ensino superior: estudo de caso. 2011. Dissertação (Pós-graduação em Ciência da Computação) - Universidade Federal de Pernambuco, Recife, 2011.

INSTITUTO BRASILEIRO DE GOVERNANÇA CORPORATIVA (IBGC). Governança Corporativa. [2017]. Disponível em: http://www.ibgc.org.br/governanca/governanca-corporativa. Acesso em: 10 fev. 2017.

ISACA. COBIT 5 a business framework for the governance and management of enterprise IT. Isaca. 2012, $98 \mathrm{p}$.

MADDALENA, Victor. Governance, public participation and accountability: To whom are regional health authorities accountable? Healthcare Management Forum, v. 19, n. 3, p. 32-37, 2006.

MARQUES, Maria da Conceição da Costa. Aplicação dos princípios da governança corporativa aplicada ao setor público. Revista de Administração Contemporânea, Rio de Janeiro, v. 11, n. 2, p. 11-26, abr./jun. 2007.

SEGATTO-MENDES, Andréa Paula; ROCHA, Keiler Carvalho. C. Contribuições da teoria de agência ao estudo dos processos de cooperação tecnológica universidade-empresa. Revista de Administração, São Paulo, v. 40, n. 2, p. 172-183, abr./jun. 2005. 
NASCIMENTO, J osé Aguiar do. Alinhamento estratégico da TI: 0 caso da UFRN. 2014. 72f. Dissertação (Mestrado) - Centro de Ciências Sociais Aplicadas, Universidade Federal do Rio Grande do Norte, Natal, 2014.

OLIVEIRA, Luciel Henrique de. Exemplo de cálculo de Ranking Médio para Likert. Notas de Aula. Metodologia Científica e Técnicas de Pesquisa em Administração. Mestrado em Adm. e Desenvolvimento Organizacional. PPGA CNEC/FACECA: Varginha, 2005.

PUTZ, Rosane Beatriz Zanetti. Governança de TI nas universidades federais brasileiras: uma abordagem integrada. 2015. Dissertação (Mestrado) - Programa de Pós-graduação em Planejamento e Governança Pública, Universidade Tecnológica Federal do Paraná, Curitiba, 2015.

SAMPIERI, Roberto Hernandez; COLLADO, Carlos Fernández; LUCIO, María del Pilar Baptista. Metodologia de pesquisa. 5. ed. Porto Alegre: AMGH, 2013.

SILVA, J osé Sérgio Santos da. Tecnologia da informação como elemento de qualificação da gestão estratégica da Universidade Federal do Recôncavo da Bahia. 2016. Dissertação (Mestrado Profissional) Programa de Pós-graduação em Gestão de Políticas Públicas e Segurança Social, Universidade Federal do Recôncavo da Bahia, Cruz das Almas, 2016.

TCU. Governança Pública: referencial básico de governança aplicável a órgãos e entidades da administração pública e ações indutoras de melhoria. Brasília: TCU, Secretaria de Planejamento, Governança e Gestão. Brasília, DF, 2014. 96p.

Acórdão no 882/2017 - Plenário. [2017] Disponível em:

https://contas.tcu.gov.br/pesquisal urisprudencia/\#/detalhamento/11/\%252a/NUMACORDAO\%253A882\%25 20ANOACORDAO\%253A2017/DTRELEVANCIA\%2520desc\%252C\%2520NUMACORDAOINT\%2520desc/false/1 /false . Acesso em: 10 jun. 2017.

UFRB - Universidade Federal do Recôncavo da Bahia. Institucional. [2006] Disponível em: https://www.ufrb.edu.br/portal/institucional . Acesso em: 05 dez. 2015.

Resolução no 005/2014. [2014] Disponível em:

https://ufrb.edu.br/soc/components/com_chronoforms5/chronoforms/uploads/documento/resolucao-0514-consuni.pdf. Acesso em: 05 jan. 2018

Plano de Desenvolvimento Institucional 2015 - 2019. [2015]. Disponível em: https://ufrb.edu.br/soc/images/PDI/PDI_2_ETAPA_28_07_2016.pdf. Acesso em: 10 fev. 2018.

Portaria no 721. [2016a]. Disponível em: https://ufrb.edu.br/reitoria/components/com_chronoforms5/chronoforms/uploads/cadastroportarias/20160926095812_Portaria_721-2016.pdf. Acesso em: 05 jan. 2018.

Relatório de Gestão. [2016b]. Disponível em: https://ufrb.edu.br/proplan/documentos/category/8relatorio-de-gestao. Acesso em: 10 fev. 2018.

Relatório de Gestão. [2017]. Disponível em: https://ufrb.edu.br/proplan/documentos/category/8relatorio-de-gestao. Acesso em: 10 fev. 2018.

VAN GREMBERGER, W. Strategies for information technology governance. 0 Hershey, PA: Idea Group Publishing, 2004.

WEILL, Peter; ROSS, J eanne W. Governança de tecnologia da informação. São Paulo: Makron Books do Brasil, 2006. 